Article

\title{
The Evaluation of Clay Suitability for Geopolymer Technology
}

\author{
Tomáš Hanzlíček ${ }^{1}$, Ivana Perná ${ }^{1, *(\mathbb{D})}$, Kateřina Uličná ${ }^{2}$, Václav Římal ${ }^{2}$ (D) \\ and Helena Štěpánková 2 \\ 1 Institute of Rock Structure and Mechanics, The Czech Academy of Sciences, V Holešovičkách 41, \\ 18209 Prague 8, Czech Republic; hanzlicek@irsm.cas.cz \\ 2 Faculty of Mathematics and Physics, Charles University, V Holešovičkách 2, 18000 Prague 8, Czech Republic; \\ Katerina.Ulicna@mff.cuni.cz (K.U.); Vaclav.Rimal@mff.cuni.cz (V.̌̌.); Helena.Stepankova@mff.cuni.cz (H.Š.) \\ * Correspondence: perna@irsm.cas.cz; Tel.: +420-26-600-9253; Fax: +420-28-468-0105
}

Received: 12 August 2020; Accepted: 23 September 2020; Published: 26 September 2020

\begin{abstract}
In the last 20 years, laboratory work on geopolymer technology has been confronted with the necessity to determine whether a certain clay material has the properties necessary to form genuine geopolymer when thermally treated and alkalized. The assessment of the properties of clay source materials and of the ability of the materials to form geopolymer 3D netting mainly involves the study of the aluminum transformation level during the thermal treatment of the clay. The presented study combines several classical analytical methods (chemical and mineralogical analyses, the calculation of the Hinckley index (HI) based on X-ray diffraction analyses, and the measurement of particle size distribution) for eleven samples of kaolin and kaolinitic clay of various origins and coming from different locations. The results of these methods have been compared with those of ${ }^{27} \mathrm{Al}$ magic angle spinning nuclear magnetic resonance (MAS NMR) in solid state. Based on them, the mentioned methods could be combined for an estimation of the aluminum-ion behavior during the thermal treatment of the clay. HI calculations have shown favorable agreement in $63 \%$ of the kaolin samples studied, especially for high purity kaolin without significant impurities in the form of feldspars and/or quartz. The main aim of this work is not to replace the precise MAS-NMR analysis, but to offer an alternative evaluation method when MAS-NMR is not available.
\end{abstract}

Keywords: kaolin; Hinckley index; lattice defect; XRD; MAS NMR in solid state

\section{Introduction}

The trend in the recognition of clay suitability for geopolymer technology is closely associated with the use of many different local sources of clay materials. It is well known that clay should be transformed (activated) in the sense of changing its aluminum-ion coordination [1-3]. This activation involves thermal treatment, during which dehydroxylation is followed by a destruction of the double-layer clay lattice (e.g., kaolin, dickite, and nacrite). $\mathrm{Al}^{3+}$ ions change their orientation from natural sixcoordination to metastable five- and partially also four- coordination to the oxygen [3-6].

The work of many laboratories and institutions utilizing geopolymer technology based on metakaolin is limited by the use of local clay. The origin and nature of kaolin and kaolinitic clay deposits fundamentally influence their affinity to form geopolymer-matrix precursors [7,8]. It has been confirmed [2,9-11] that only four- and five-coordinated aluminum ions are in a state in which subsequent alkalization results in a stable polycondensed system. The alumino-silicates form a 3D network of the solid matter where the unbalanced four-/five-coordinated aluminum ion is balanced by alkali cations [3,4,12-15]. Geopolymers are predominantly amorphous materials, whose properties mainly depend on the clay material used and its thermal activation, on the alkaline activator utilized 
$\left(\mathrm{Na}^{+}, \mathrm{K}^{+}\right.$, or $\left.\mathrm{Ca}^{2+}\right)$ and on the amount and type of the filler $[2-5,7,10]$. In general, geopolymers have excellent physical and chemical properties, such as high strength, low leachability, and high resistance to aggressive solutions. They are also non-flammable and resistant to high temperatures $[2-5,8,12,13]$.

The first estimation if the clay material is suitable for geopolymer preparation consisted in the identification of chemical analysis, followed by roentgen diffraction study, and complemented by the measurement of particle size distribution. Previous studies have shown that the affinity of the changes in $\mathrm{Al}^{3+}$ coordination in double-layer clay depends on temperature and the dwell at the maximum level. It has also been found that these transformations depend on the following conditions:

- $\quad$ the crystallinity of clay (well or poorly ordered kaolinite) [10].

- the number of the aluminum ions affected during the thermal treatment.

- $\quad$ a high amount of small-particle clay after the thermal treatment [16].

The commonly used X-ray diffraction in combination with chemical analysis and the measurement of particle size distribution could be used for the estimation of the ability of clay to form geopolymer precursor. Most discussion has been focused on a method that would resolve the organization and crystallinity degree of kaolin. The degree of crystallinity and its impact on defects in the kaolin lattice have been studied by many researchers [17-21]. The last computerized method for the study of well-ordered kaolin was created by Plaçon and Zacharie (1990) [22], taking into consideration eleven values from powdered roentgen analyses (EXSY (2D exchange spectroscopy) method). Another work on the same subject was published in 1999 by Aparicio et al. [23], presenting the AGFI (Aparicio-Galán-Ferrell index) system. The number of studies on the structures and the intentions to define the ordering or disordering of the clay lattice show the importance of the knowledge of how the crystal structure is organized.

For the semi-quantitative evaluation of the degree of disorderliness of the kaolin lattice, it is common to use the Hinckley index (HI), published in 1963, for its relative simplicity. For the quantification of the influences of the crystallinity level on specific defects, the HI method is not sufficient [24]. When the value of the Hinckley index is below 1, the kaolinite lattice is disordered, and consequently, the aluminum ion is more easily transformable. It is supposed that a firmly organized lattice with fewer vacancies and crystal imperfections will be more resistant, particularly to changes in aluminum-ion coordination.

Chemical analyses and ideal stoichiometric calculations indicate the content of accompanying clay minerals (e.g., quartz, feldspars, micas, carbonates, metallic oxides, etc.). The content of carbonates and metal oxides could change the particle size distribution by sintering in solid state during the thermal treatment of clay. However, these clay impurities do not affect the formation of geopolymers or their resulting properties $[3,4,7]$.

There are some suppliers of industrially prepared "metakaolin", but most institutions and laboratories work with the local raw clay. Therefore, it is necessary to determine the quality of the clay and optimize its thermal treatment and temperature dwell. This article focuses on the characterization of different types of kaolin and kaolinitic clay from very distant places and of diverse nature. The samples have been studied in terms of their chemical and mineralogical compositions and particle size distribution.

The identification of kaolin properties, especially the state of aluminum coordination after thermal treatment is exactly monitored by ${ }^{27} \mathrm{Al}$ magic angle spinning-nuclear magnetic resonance (MAS-NMR) in solid state [25-28]. The resonance frequencies of ${ }^{27} \mathrm{Al}$ MAS NMR are sensitive to the local atomic arrangement in the vicinity of an aluminum ion, which makes it possible to distinguish between spectral contributions according to the aluminum coordination to the neighboring oxygens. The ${ }^{27} \mathrm{Al}$ MAS NMR in solid state could be used not only for the determination of aluminum coordination after thermal treatment, but also for the observation of transformation processes during the formation of the geopolymer $[10,14,29,30]$.

Although the MAS NMR identification of the aluminum-ion shift is the most exact method, only some institutions possess the magnetic-resonance device. The main focus of this article is to offer 
a combination of three commonly available analytical methods for the estimation of the aluminum-ion behavior during thermal treatment, and thus for the identification of the ability of clay to form a genuine geopolymer without its being necessary to use MAS NMR devices.

\section{Experimental Part}

The laboratory is mainly focused on the utilization of unused clay or by-product clay materials, which in enormous quantities remain heaped or are recollected in waste ponds. These include (A) kaolin clay washed out from sandstone (the main product: white sand used for the glass industry); (B) kaolin supplied by industrial producers; (C) kaolin from unused deposits; (D) kaolin from abroad.

\subsection{Materials}

A. Kaolin clay washed out from sandstone

- Strelec (East-North Bohemia, Czech Republic), a by-product of quartz-sand extraction from sedimentary sandstone (formed in the Cretaceous Period). Yellowish kaolinitic clay fixing the snow-white sand (used in glass production) is washed out during the extraction procedure and deposited in sludge ponds without use. The kaolin has been treated and washed in a laboratory.

- Provodin (North Central Bohemia, Czech Republic), a by-product washed out during the industrial extraction of quartz sand (used in glass production) from sedimentary sandstone (formed in the Cretaceous period), deposited without use. The kaolin has been treated and washed in a laboratory.

B. Kaolin supplied by industrial producers

- $\quad$ Sedlec (West Bohemia, Czech Republic), the most important kaolin, utilized for its properties in the production of fine tableware in Carlsbad. Industrially washed and supplied kaolin, known also as the World Whiteness Standard since 1928, is used mainly in the porcelain industry.

- Kadan (North-West Bohemia, Czech Republic), kaolin formed as enormous pocket-like formations in the coal basin, used as a whitening additive in paper fabrication.

- Kaznejov (South-West Bohemia, Czech Republic), kaolin used mainly for floor- and wall-tile production.

C. Kaolin from unused deposits

- $\quad$ Ledce (West Bohemia, Czech Republic), a drained ancient deposit, formerly used in the production of wall tiles. The kaolin has been treated and washed in a laboratory.

- Vidnava (North Moravia, Czech Republic), a hardly accessible deposit, formerly used for floor- and wall-tile production and as an additive in paper fabrication. The kaolin has been treated and washed in a laboratory.

D. Kaolin from abroad

- Sri Lanka-a deposit close to the village of Bombuwala, used in pottery production. The kaolin has been treated and washed in a laboratory.

- Brazil "B" and Brazil "R" - two different kaolin deposits in South Brazil. Industrially washed and supplied kaolin of unknown use. The samples have been obtained within the framework of international cooperation.

- Ukraine (Prosyanaya deposit), kaolin used in the manufacture of paper, ceramics, refractory materials, paints, fiberglass, plastics, rubber, sealants, and adhesives.

Commercially supplied kaolin is available in high purity as a dry, milled powder. Kaolin from other sources is predominantly in the raw state, i.e., solid lumps containing both organic and inorganic 
impurities, especially quartz sand. For this reason, the raw samples of Vidnava, Ledce and Sri Lanka kaolin were treated in laboratory conditions by a Schulz Column. All clay samples were dried and analyzed in powdered state.

\subsection{Material Treatment}

\subsubsection{Laboratory Washing of Untreated Kaolin}

The Schulz Column works on the principle of the separation of clay-particle sizes through the gravity in water suspension (Figure 1A,B). The laboratory device consists of the column with the cylinder of $100 \mathrm{~mm}$ in diameter and $600 \mathrm{~mm}$ in length. In its center, it has a glass tube (with a diameter of $10 \mathrm{~mm}$ ), terminated by an enlargement forming an inverted funnel, leaving the distance of a max. of $20 \mathrm{~mm}$ from the cylinder wall. The distance of the funnel from the cylinder bottom is $60 \mathrm{~mm}$. It is possible to fix the glass tube higher or lower depending on the desired particle size. What is the most important is the flux velocity of the kaolin suspension through the glass tube and the difference in the flux velocity given by the difference between the glass tube and the cylinder diameter. The kaolin suspension is supplied by a pulse pump, where the rubber tube is connected to the upper side of the glass tube (i). The column works based on the difference between the tube and cylinder diameters, where the flux velocity in the glass tube is considerably higher than the velocity of the flux in the cylinder, and the inverted funnel avoids suspension turbulence. Practically all complementing clay particles, such as sand, the remaining feldspar, and other impurities, sediment at the cylinder bottom (ii). The external collar over the column top collects the suspension of the washed kaolin (iii). After the sedimentation and filtration, the washed samples are dried for further studies.
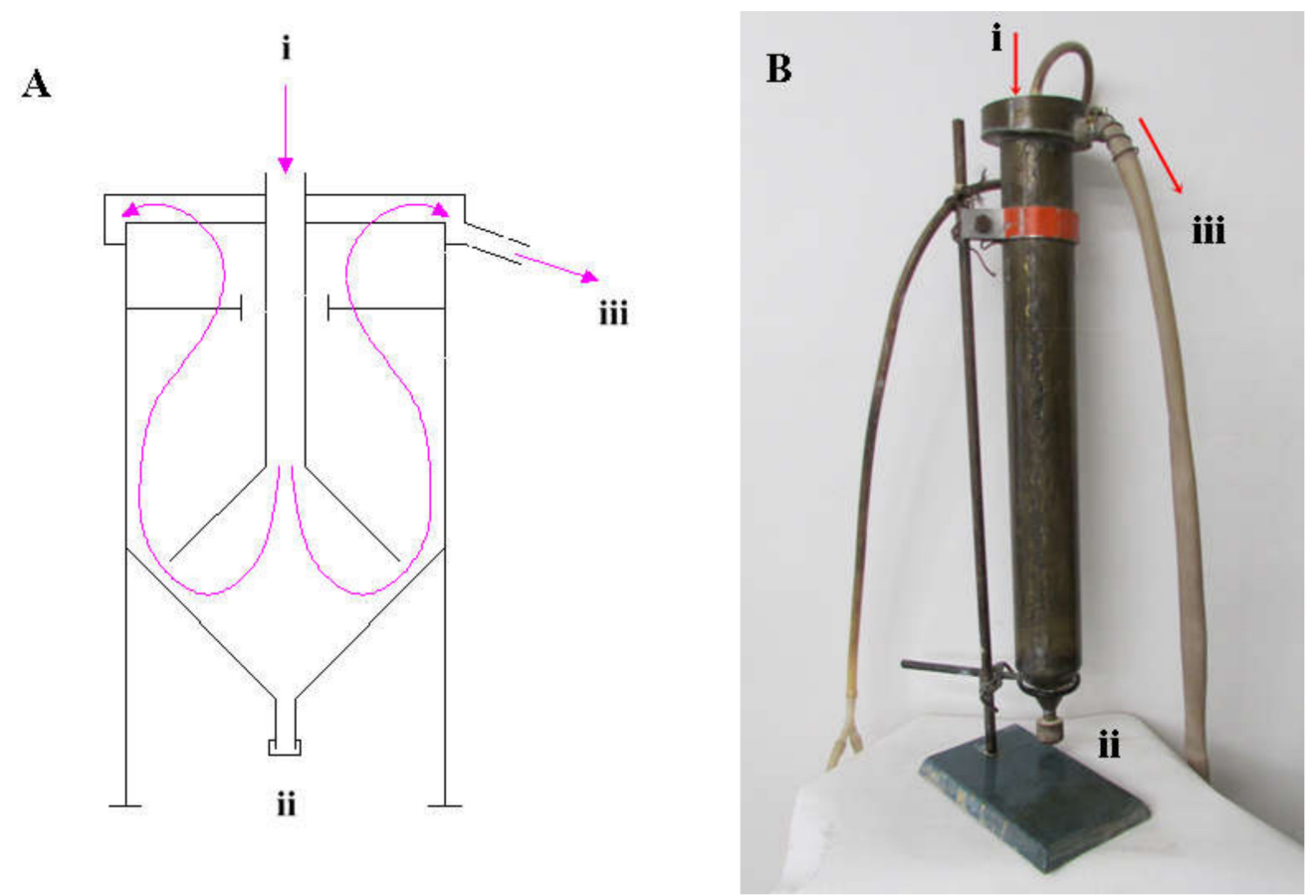

Figure 1. Schulz Column (A-the basic scheme, B-real Schulz Column).

\subsubsection{Thermal Treatment of Kaolin}

The values of temperature and dwell presented in the literature differ depending on the kaolin applied [5,31,32]. The common transformation temperature of $750^{\circ} \mathrm{C}$ and dwell of $4 \mathrm{~h}$ used for standard kaolins were chosen. This dwell was selected as a default value for a sample comparison although it could be expected that this dwell would not be sufficient for the complete transformation of aluminum ions in some samples. 
The thermal treatment of all types of kaolin was carried out in an electric kiln (BVD KY100, Czech Republic) with a heating gradient of $5{ }^{\circ} \mathrm{C} / \mathrm{min}$ and natural cooling inside the kiln.

\subsubsection{Geopolymer Preparation}

All geopolymers were prepared with the same procedure, using the soluble potassium silicate (potassium silicate 3.0, supplied by Vodní sklo a.s., Prague, Czech Republic) and a powdered sample after thermal treatment. The solution (with the molar ratio of $\mathrm{SiO}_{2}: \mathrm{K}_{2} \mathrm{O}: \mathrm{H}_{2} \mathrm{O}$ being 1.71:1.00:9.14) was slowly filled with the powdered sample and mixed in an ordinary food processor for $15 \mathrm{~min}$. The obtained homogenous liquid was poured into plastic boxes and firmly closed with plastic lids. All experiments were performed in ambient laboratory conditions. The geopolymers were obtained using the standardized molar ratios for all samples. The molar ratios used in these experiments were:

$$
\mathrm{SiO}_{2} / \mathrm{Al}_{2} \mathrm{O}_{3}=3.2: 1 \mathrm{~K}_{2} \mathrm{O} / \mathrm{Al}_{2} \mathrm{O}_{3}=0.75: 1 \mathrm{H}_{2} \mathrm{O} / \mathrm{K}_{2} \mathrm{O}=12: 1
$$

The geopolymer characteristic is defined by formation of a hard, insoluble material (photographs of geopolymer solids in Supplementary file, Part A-Supplementary Figures S1-S11). The setting and hardening time is presented in Table 1 for all eleven studied kaolin. The confirmation of the formatted 3D netting could be controlled by FTIR analysis defining the Al-O-Si clusters. According to the previous definition of the vibrations corresponding to these netting the genuine geopolymer is confirmed (Supplementary file, Part B-Supplementary Figures S12-S22).

Table 1. The Setting and Hardening Time of Kaolin and Kaolinitic Clay Used.

\begin{tabular}{cc}
\hline Place & Setting and Hardening Time (Hours) \\
\hline Kadan & 8 \\
Ledce & 8 \\
Sedlec & 10 \\
Strelec & 12 \\
Vidnava & 7 \\
Kaznejov & 12 \\
Provodin & 12 \\
Sri Lanka & 2 \\
Ukraine & 7 \\
Brazil “B” & 6 \\
Brazil "R" & 6 \\
\hline
\end{tabular}

Table 1 has demonstrated the differences in setting and hardening time between kaolin samples. The average time ranged from 6 to $12 \mathrm{~h}$ (Brazil "B" and Brazil "B" samples and Strelec, Kaznejov and Provodin samples, respectively). The only exception is Sri Lanka kaolin, which solidifies extremely quickly in $2 \mathrm{~h}$.

\section{Methods}

Chemical analyses of selected types of kaolin and kaolinitic clay were performed by an X-ray-fluorescence (XRF) analyzer (Spectro IQ, Kleve, Germany) in an atmosphere of helium. The target material was palladium and the target angle from the central ray was $90^{\circ}$. The focal point was a $1 \times 1 \mathrm{~mm}$ square, and the maximum anode dissipation was 50 Watts with 10 -cfm forced-air cooling. The tested samples were prepared by the pressed-pellet method.

The loss of ignition (LOI) was determined on pre-dried and pulverized samples $\left(105^{\circ} \mathrm{C}\right.$ until constant weight, particle size: $0-0.2 \mathrm{~mm}$ ) at a temperature of $1000^{\circ} \mathrm{C}$ with a dwell of $10 \mathrm{~min}$ in a muffle furnace (a temperature rise of $10^{\circ} \mathrm{C} / \mathrm{min}$, air atmosphere). 
The particle size distribution was measured by a CILAS 920L analyzer, using clay suspension in water and detecting particle sizes by the laser-beam reflection, recalculating the distribution of the particles through Fourier transform methods.

The X-ray diffraction (XRD) examination of the crystallographic phases was performed with an $X^{\prime}$ Pert PRO $\theta-\theta$ powder diffractometer with parafocusing Bragg-Brentano geometry using $\mathrm{Cu}$ $\mathrm{K} \alpha$ radiation $(\lambda=1.5418 \AA$, generator setting: $40 \mathrm{kV}, 30 \mathrm{~mA})$. An ultrafast $X^{\prime}$ Celerator detector was employed over the angular range of $7-70^{\circ}(2 \theta)$ with a step size of $0.017^{\circ}(2 \theta)$ and the counting time of $20.00 \mathrm{~s} \cdot \mathrm{step}^{-1}$. The data were evaluated using the High Score Plus V 3.0e PANalytical software package (Almelo, The Netherlands).

The kaolin crystallinity level was determined by the Hinckley index (HI), a relatively old method described by Hinckley [16], taking advantage of commonly used XRD analysis. The method of Hinckley-index calculation is the following [17]: The line drawn between the reflections 020 and 111 defines the heights of the peaks at 110 (A) and 111 (B) at $2 \Theta$ equal to $20.4^{\circ}$ and $21.3^{\circ}$, respectively. Their sum is divided by the height of the 110 peak above the general background (At). The most important information obtained through the HI calculation is that a lower index means a poorly organized kaolinite lattice. A firmly organized lattice with lower vacancies may be more resistant to the changes of aluminum-ion coordination.

All the ${ }^{27}$ Al MAS NMR spectra presented were measured in an external magnetic field of $11.7 \mathrm{~T}$ using a Bruker Avance 500 NMR spectrometer equipped with a 4-mm MAS probe head. The ${ }^{27} \mathrm{Al}$ MAS NMR spectra were acquired at $130.3233 \mathrm{MHz}$; the spinning frequency was $14 \mathrm{kHz}$; the width of the applied $\pi / 12$ pulse was $1.33 \mu \mathrm{s}$; the recycle delay was $5 \mathrm{~s}$. The number of scans was 1600 , and the dwell time was $0.8 \mu$ s (a spectral width of $625 \mathrm{kHz}$ ). The spectra were referenced to a $1 \mathrm{M}$ solution of $\mathrm{Al}\left(\mathrm{NO}_{3}\right)_{3}(0.0 \mathrm{ppm})$ in water. They were decomposed into three main patterns: line 1 (four-coordination, near 58 ppm), line 2 (five-coordination, near 38-40 ppm), and line 3 (six-coordination, near 0 ppm).

\section{Results and Discussion}

Eleven different samples of kaolinitic clay and kaolin, described in Section 2.1, were studied in terms of their chemical and mineralogical compositions (Tables 2 and 3, respectively) and particle size distribution. The kaolin lattice ordering was calculated on the basis of XRD patterns, and these results were compared with MAS NMR analysis of the $\mathrm{Al}^{3+}$ shift of kaolin thermally treated at $750{ }^{\circ} \mathrm{C}$ (a four-hour dwell).

Table 2. The Chemical Analysis of the Samples of Kaolin and Kaolinitic Clay Used (in wt. \%).

\begin{tabular}{ccccccccc}
\hline Place & $\mathrm{SiO}_{\mathbf{2}}$ & $\mathrm{Al}_{\mathbf{2}} \mathbf{O}_{\mathbf{3}}$ & $\mathbf{K}_{\mathbf{2}} \mathbf{O}$ & $\mathbf{C a O}$ & $\mathrm{Na}_{\mathbf{2}} \mathbf{O}$ & $\mathbf{F e}_{\mathbf{2}} \mathbf{O}_{\mathbf{3}}$ & $\mathrm{TiO}_{\mathbf{2}}$ & $\mathbf{L O I}$ \\
\hline Kadan & 46.81 & 36.57 & 1.37 & 0.08 & 0.11 & 1.22 & 0.53 & 13.00 \\
Ledce & 46.56 & 34.78 & 1.16 & 1.89 & 0.11 & 0.68 & 0.78 & 13.62 \\
Sedlec & 46.97 & 36.64 & 1.14 & 0.32 & $<0.11$ & 1.14 & 0.19 & 13.00 \\
Strelec & 67.86 & 24.69 & 0.28 & 0.03 & $<0.11$ & 0.35 & 0.29 & 6.08 \\
Vidnava & 54.55 & 34.49 & 0.96 & 0.25 & 0.11 & 2.09 & 0.94 & 5.99 \\
Kaznejov & 55.60 & 31.85 & 1.61 & 0.11 & 0.10 & 0.60 & 1.05 & 8.70 \\
Provodin & 72.05 & 19.23 & 2.52 & 0.18 & 0.10 & 1.06 & 0.25 & 4.20 \\
Sri Lanka & 48.02 & 38.17 & 0.19 & 0.05 & 0.09 & 0.88 & 1.05 & 11.44 \\
Ukraine & 45.61 & 37.57 & 0.75 & 0.21 & $<0.11$ & 1.08 & 0.88 & 10.20 \\
Brazil “B” & 45.96 & 36.40 & 1.03 & 0.75 & $<0.11$ & 1.20 & 0.14 & 14.05 \\
Brazil "R" & 46.23 & 37.87 & 0.38 & 0.43 & $<0.11$ & 1.41 & 0.15 & 13.10 \\
\hline
\end{tabular}


Table 3. The Mineralogy of the Types of Clay Studied (Based on XRD Analyses).

\begin{tabular}{|c|c|c|c|}
\hline Place & Major Phases & Minor Phases & Traces \\
\hline Kadan & kaolinite $\left(\mathrm{Al}_{2} \mathrm{O}_{3} \cdot 2 \mathrm{SiO}_{2} \cdot 2 \mathrm{H}_{2} \mathrm{O}\right)$ & muscovite $\left(\mathrm{KAl}_{2}(\mathrm{Si}, \mathrm{Al})_{4} \mathrm{O}_{10}(\mathrm{OH})_{2}\right)$ & - \\
\hline Ledce & kaolinite $\left(\mathrm{Al}_{2} \mathrm{O}_{3} \cdot 2 \mathrm{SiO}_{2} \cdot 2 \mathrm{H}_{2} \mathrm{O}\right)$ & calcite $\left(\mathrm{CaCO}_{3}\right)$ & $\begin{array}{c}\text { rutile }\left(\mathrm{TiO}_{2}\right) \\
\text { muscovite }\left(\mathrm{KAl}_{2}(\mathrm{Si}, \mathrm{Al})_{4} \mathrm{O}_{10}(\mathrm{OH})_{2}\right)\end{array}$ \\
\hline Sedlec & kaolinite $\left(\mathrm{Al}_{2} \mathrm{O}_{3} \cdot 2 \mathrm{SiO}_{2} \cdot 2 \mathrm{H}_{2} \mathrm{O}\right)$ & muscovite $\left(\mathrm{KAl}_{2}(\mathrm{Si}, \mathrm{Al})_{4} \mathrm{O}_{10}(\mathrm{OH})_{2}\right)$ & - \\
\hline Strelec & quartz $\left(\mathrm{SiO}_{2}\right)$ & kaolinite $\left(\mathrm{Al}_{2} \mathrm{O}_{3} \cdot 2 \mathrm{SiO}_{2} \cdot 2 \mathrm{H}_{2} \mathrm{O}\right)$ & $\begin{array}{c}\text { rutile }\left(\mathrm{TiO}_{2}\right) \\
\text { muscovite }\left(\mathrm{KAl}_{2}(\mathrm{Si}, \mathrm{Al})_{4} \mathrm{O}_{10}(\mathrm{OH})_{2}\right)\end{array}$ \\
\hline Vidnava & kaolinite $\left(\mathrm{Al}_{2} \mathrm{O}_{3} \cdot 2 \mathrm{SiO}_{2} \cdot 2 \mathrm{H}_{2} \mathrm{O}\right)$ quartz $\left(\mathrm{SiO}_{2}\right)$ & calcite $\left(\mathrm{CaCO}_{3}\right)$ & $\begin{array}{c}\text { rutile }\left(\mathrm{TiO}_{2}\right) \\
\text { muscovite }\left(\mathrm{KAl}_{2}(\mathrm{Si}, \mathrm{Al})_{4} \mathrm{O}_{10}(\mathrm{OH})_{2}\right)\end{array}$ \\
\hline Kaznejov & kaolinite $\left(\mathrm{Al}_{2} \mathrm{O}_{3} \cdot 2 \mathrm{SiO}_{2} \cdot 2 \mathrm{H}_{2} \mathrm{O}\right)$ & $\begin{array}{c}\text { quartz }\left(\mathrm{SiO}_{2}\right) \\
\text { muscovite }\left(\mathrm{KAl}_{2}(\mathrm{Si}, \mathrm{Al})_{4} \mathrm{O}_{10}(\mathrm{OH})_{2}\right)\end{array}$ & apophyllite $\left(\mathrm{KCa}_{4} \mathrm{Si}_{8} \mathrm{O}_{20}(\mathrm{O} \mathrm{H}) \cdot 8 \mathrm{H}_{2} \mathrm{O}\right)$ \\
\hline Provodin & quartz $\left(\mathrm{SiO}_{2}\right)$ & kaolinite $\left(\mathrm{Al}_{2} \mathrm{O}_{3} \cdot 2 \mathrm{SiO}_{2} \cdot 2 \mathrm{H}_{2} \mathrm{O}\right)$ & $\begin{array}{c}\text { muscovite }\left(\mathrm{KAl}_{2}(\mathrm{Si}, \mathrm{Al})_{4} \mathrm{O}_{10}(\mathrm{OH})_{2}\right) \\
\text { microcline }\left(\mathrm{KAlSi}_{3} \mathrm{O}_{8}\right)\end{array}$ \\
\hline Sri Lanka & kaolinite $\left(\mathrm{Al}_{2} \mathrm{O}_{3} \cdot 2 \mathrm{SiO}_{2} \cdot 2 \mathrm{H}_{2} \mathrm{O}\right)$ & - & - \\
\hline Ukraine & kaolinite $\left(\mathrm{Al}_{2} \mathrm{O}_{3} \cdot 2 \mathrm{SiO}_{2} \cdot 2 \mathrm{H}_{2} \mathrm{O}\right)$ & rutile $\left(\mathrm{TiO}_{2}\right)$ & - \\
\hline Brazil “B” & kaolinite $\left(\mathrm{Al}_{2} \mathrm{O}_{3} \cdot 2 \mathrm{SiO}_{2} \cdot 2 \mathrm{H}_{2} \mathrm{O}\right)$ & $\begin{array}{c}\text { rutile }\left(\mathrm{TiO}_{2}\right) \\
\text { quartz }\left(\mathrm{SiO}_{2}\right) \\
\text { albite }\left(\left(\mathrm{Na}_{0.75} \mathrm{Ca}_{0.25}\right)\left(\mathrm{A}_{11.26} \mathrm{Si}_{2.74} \mathrm{O}_{8}\right)\right) \\
\text { muscovite }\left(\mathrm{KAl}_{2}(\mathrm{Si}, \mathrm{Al})_{4} \mathrm{O}_{10}(\mathrm{OH})_{2}\right)\end{array}$ & - \\
\hline Brazil “R” & kaolinite $\left(\mathrm{Al}_{2} \mathrm{O}_{3} \cdot 2 \mathrm{SiO}_{2} \cdot 2 \mathrm{H}_{2} \mathrm{O}\right)$ & $\begin{array}{c}\text { rutile }\left(\mathrm{TiO}_{2}\right) \\
\text { quartz }\left(\mathrm{SiO}_{2}\right) \\
\text { albite }\left(\left(\mathrm{Na}_{0.75} \mathrm{Ca}_{0.25}\right)\left(\mathrm{A}_{11.26} \mathrm{Si}_{2.74} \mathrm{O}_{8}\right)\right)\end{array}$ & - \\
\hline
\end{tabular}


Table 2 presents the amount of the main oxides in wt. \% recalculated from XRF elemental analysis. The XRD patterns are presented in Supplementary Figures S23-S33 (Supplementary file, Part C).

The mineralogical compositions of all samples are summarized in Table 3. The X-ray diffractions of kaolin have proven the expected presence of kaolinite and the occurrence of quartz, muscovite, calcite, feldspars (albite, microcline), rutile and traces of a zeolite structure (apophyllite).

Theoretically, according to the ideal formula of kaolinite $\left(\mathrm{Al}_{2} \mathrm{O}_{3} \cdot 2 \mathrm{SiO}_{2} \cdot 2 \mathrm{H}_{2} \mathrm{O}\right)$, the LOI value of pure kaolinite should be higher than $13.0 \mathrm{wt}$. \%. Chemical analyses facilitate the orientation in the mineral composition using the ideal stoichiometric formula of the corresponding minerals. Table 4 presents the calculated theoretical content of kaolinite which is crucial for the estimation of the aluminum ions that can be transformed during thermal activation. This table also includes quartz because it is contained in the "waste clay" from Provodin and Strelec. The information on the nature of clay is complemented by the content of quartz, feldspar, muscovite, and calcite. However, these minerals do not participate in the geopolymer reaction.

Table 4. The Calculated Theoretical Content of Kaolinite and Quartz in Clay Samples.

\begin{tabular}{cccc}
\hline Content/Place & Kaolinite (wt. \%) & Quartz (wt. \%) & Others (wt. \%) \\
\hline Kadan & 87.9 & - & 10.4 \\
Ledce & 83.6 & - & 15.7 \\
Sedlec & 90.8 & - & 7.86 \\
Strelec & 41.6 & 44.9 & 13.3 \\
Vidnava & 45.3 & 44.5 & 6.9 \\
Kaznejov & 60.9 & 33.5 & 3.5 \\
Provodin & 30.1 & 58.0 & 10.1 \\
Sri Lanka & 82.0 & 9.7 & - \\
Ukraine & 81.8 & 9.6 & - \\
Brazil “B” & 83.0 & 8.9 & 6.8 \\
Brazil “R" & 89.0 & 6.9 & 2.5 \\
\hline
\end{tabular}

In Table 4, there is a discrepancy with the interpretation of XRD results (Table 3 ). The approximation of kaolinite content is based on the ideal formulas of kaolinite, feldspars and calcite which should differ from reality, especially in the cases of kaolin from tropical countries. The largest theoretical content of kaolinite can be found in kaolin Sedlec and Brazil "R" (90.8 wt. \% and 89 wt. \%, respectively). The Provodín sample has the lowest theoretical content of kaolinite (30.1 wt. \%) due to the high content of impurities, especially quartz (58 wt. \%).

However, a calculation based on theoretical composition is the first orientation about accompanying components. The assessment of feldspar content and the identification of the possible involvement of carbonates are important for future clay studies. The content of four-coordinated aluminum ions in the feldspar will increase their total determined amount and thus affect the evaluation of MAS-NMR analysis. If carbonates are detected through the identification of $\mathrm{CaO}$ and possibly $\mathrm{MgO}$, the detected LOI should reflect their amount because their quantity could affect the particle size distribution after the thermal treatment of clay. The results of particle size measurements (Table 5) have shown three remarkable exceptions in particle size distribution (see the column "up to $4 \mu \mathrm{m}$ ") in the kaolinitic clay washed out from sandstone, i.e., those from Strelec and Provodin. In these cases, the particle size distribution is highly affected by the content of the very fine particles of the quartz sand and feldspar (the Provodin sample), which was first detected through the calculation based on chemical analysis and confirmed by XRD. Unfortunately, these results (the bold figures for Strelec and Provodin) of particle size distribution do not confirm kaolin particle size distribution because of the mentioned high contamination. A specific case is the industrially supplied kaolin from the Kaznejov deposit with an extremely low content of small and very small kaolin particles (the bold figure), which does not correspond to the other industrially supplied kaolin. 
Table 5. The Particle-size Distribution in the Clay Samples Studied (wt. \%).

\begin{tabular}{ccccccc}
\hline Place/Size & $\begin{array}{c}\text { up to } \mathbf{2} \boldsymbol{\mu m} \\
\text { (wt. \%) }\end{array}$ & $\begin{array}{c}\text { up to } \mathbf{4} \boldsymbol{\mu m} \\
\text { (wt. \%) }\end{array}$ & $\begin{array}{c}\text { up to } \mathbf{1 0} \boldsymbol{\mu m} \\
\text { (wt. \%) }\end{array}$ & $\begin{array}{c}\text { up to } \mathbf{2 0} \boldsymbol{\mu m} \\
\text { (wt. \%) }\end{array}$ & $\begin{array}{c}\text { up to } \mathbf{4 5} \boldsymbol{\mu m} \\
\text { (wt. \%) }\end{array}$ & $\begin{array}{c}\text { up to } \mathbf{1 4 0} \\
\boldsymbol{\mu m} \text { (wt. \%) }\end{array}$ \\
\hline Kadan & 15.54 & 30.33 & 61.73 & 85.31 & 99.53 & 100.00 \\
Ledce & 14.98 & 36.02 & 79.40 & 98.83 & 100.00 & 100.00 \\
Sedlec & 22.31 & 42.51 & 73.21 & 91.14 & 98.91 & 100.00 \\
Strelec & 6.38 & 14.35 & 32.07 & 51.80 & 79.66 & 99.83 \\
Vidnava & 22.81 & 42.42 & 72.39 & 89.47 & 97.05 & 100.00 \\
Kaznejov & 6.41 & 13.44 & 39.49 & 72.98 & 95.56 & 100.00 \\
Provodin & 5.73 & 15.61 & 44.79 & 63.74 & 80.31 & 99.68 \\
Sri Lanka & 12.33 & 24.87 & 46.00 & 63.15 & 86.01 & 99.79 \\
Ukraine & 22.30 & 44.14 & 79.14 & 96.30 & 100.00 & 100.00 \\
Brazil “B" & 13.25 & 26.47 & 46.79 & 62.91 & 85.36 & 99.83 \\
Brazil “R" & 11.19 & 22.67 & 42.79 & 61.87 & 86.62 & 100.00 \\
\hline
\end{tabular}

The kaolin from Kadan, Ledce, Sedlec, Vidnava, and Ukraine deposits has the highest content of very small and small particles (up to 2 and $4 \mu \mathrm{m}$, respectively). Previous work has shown that this particle size is crucial for the geopolymer reaction [16]. This has also been confirmed by the setting and hardening of the geopolymers in 6-12 h.

The particle size distribution confirms the efficiency of the beneficiation of clay by the Schulz Column because the kaolin from the unused deposits (Vidnava and Ledce) and the kaolin from Sri Lanka (Ceylon) were washed by this method. The particle size distributions are similar to the samples obtained from the industrial suppliers.

Table 6 presents the calculation and measurement of the HI based on XRD analyses. The results have shown that the samples from Strelec, Kaznejov, Provodin, and Sri Lanka deposits have a high HI index. Therefore, it can be assumed that their structure is well-organized. The remaining samples have a low HI index (below 1) and their kaolinitic lattice should be disordered. The highest and the lowest values of the HI have been recorded in the kaolin from Provodin (1.22) and Ledce (0.44), respectively.

Table 6. The Calculation of the HI index Based on the XRD $(2 \Theta)$ value.

\begin{tabular}{ccccc}
\hline & \multicolumn{3}{c}{ Height (Counts) } & Hinckley Index \\
Place & A (110) & B (111) & At & H + B)/At \\
\hline Kadan & 600 & 630 & 2200 & 0.56 \\
Ledce & 430 & 400 & 1910 & 0.44 \\
Sedlec & 1100 & 1090 & 2530 & 0.87 \\
Strelec & 930 & 910 & 1550 & 1.19 \\
Vidnava & 1160 & 1110 & 3720 & 0.61 \\
Kaznejov & 730 & 800 & 1450 & 1.06 \\
Provodin & 550 & 550 & 900 & 1.22 \\
Sri Lanka & 2950 & 3100 & 5800 & 1.04 \\
Ukraine & 1160 & 1110 & 3720 & 0.61 \\
Brazil “B” & 1300 & 1000 & 3920 & 0.59 \\
Brazil "R" & 1570 & 1380 & 4550 & 0.65 \\
\hline
\end{tabular}

The presented HI results are compared with the following graph of the MAS-NMR data of all eleven samples of kaolin and kaolinitic clay (Figure 2), where the thermal treatment at $750{ }^{\circ} \mathrm{C}$ and a four-hour dwell have changed the position of $\mathrm{Al}^{3+}$ with respect to oxygen.

Based on the results, the sum of the relative proportions of four- and five-coordinated aluminum ions ranges from 62.75 to 79.13 . The lowest and the highest numbers of four-coordinated ions were recorded in Sedlec and Provodin samples, respectively. In the case of five-coordinations, the highest values have been observed for the kaolin from Sri Lanka (55.00) and Strelec (53.00). The lowest number of five-coordinated ions has been found in the Provodin kaolin 


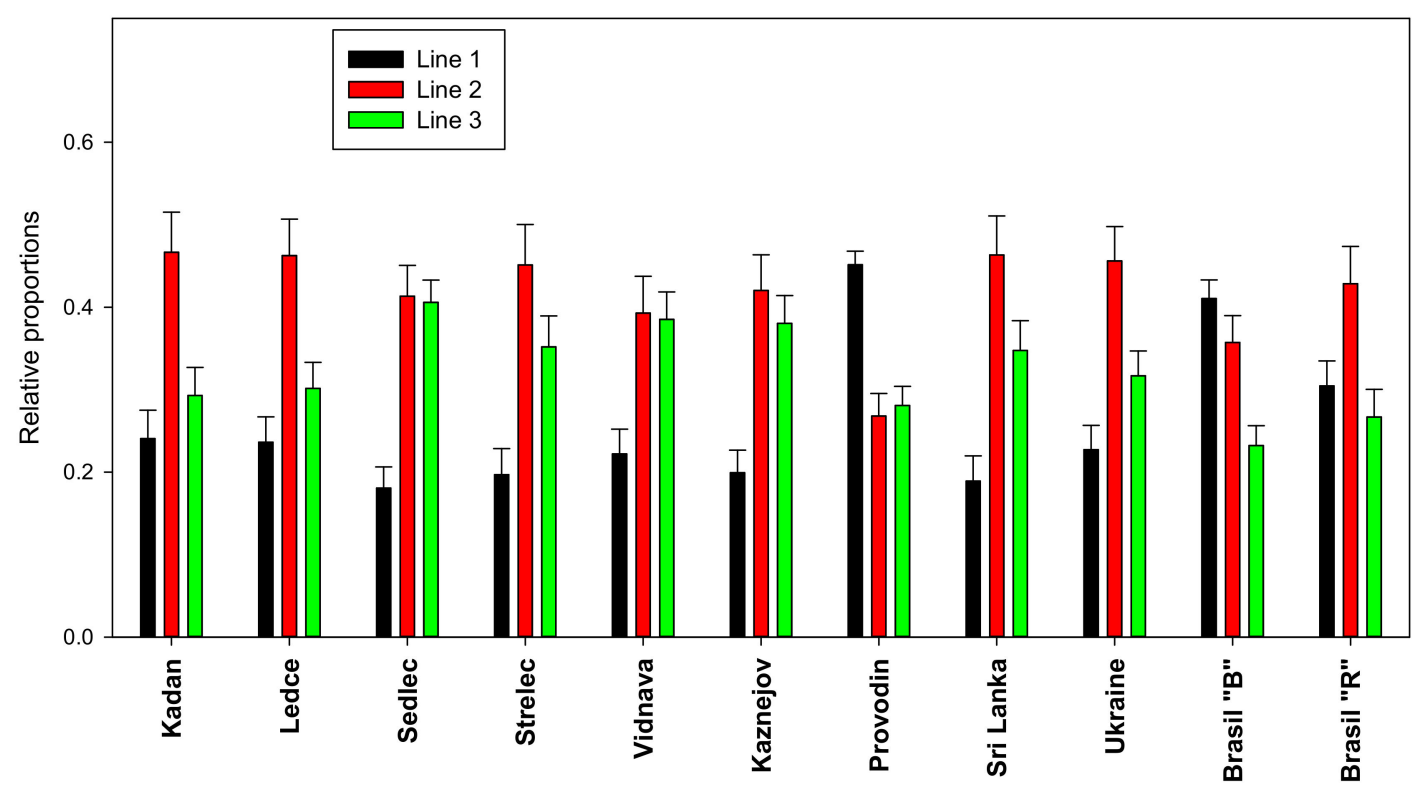

Figure 2. The proportion of the aluminum-ion coordination in the studied samples after thermal treatment $\left(4 \mathrm{~h}\right.$ at $\left.750{ }^{\circ} \mathrm{C}\right)$, obtained from ${ }^{27} \mathrm{Al}$ MAS NMR spectra (line 1-four- coordination, line 2-fivecoordination, line 3-six-coordination).

The data presented in Tables 1-6, complemented by Figure 2, can be summarized as follows.

The standardized type of thermal treatment using the identical aqueous alkali solution and the same time of mixing and curing has exhibited exceptions discussed below.

There are two types of observation: (a) the measured data and the calculation of the HI versus MAS-NMR and (b) the observation during a laboratory experiment. The (HI and MAS-NMR) results match in the majority of the compared kaolin samples that form genuine geopolymers within the time expected. A poorly ordered kaolin lattice with imperfections and vacancies $(\mathrm{HI}<1)$ creates geopolymer relatively quickly, with the setting and hardening time being between 6 and $12 \mathrm{~h}$.

Differences appear in the case of one industrially supplied kaolin —-that from Kaznejov ( $\mathrm{HI}=1.055)$. In terms of the transformation of the aluminum ion, it is similar (see lines 1 and 2 in Figure 2) to the other types of industrially supplied kaolin, but the geopolymer preparation required longer setting and hardening time because of the bigger clay particle size. Experimentally, it has been proven that the kaolin from the Kaznejov deposit gives a better result in setting and hardening time when thermally treated longer. The dwell time prolongation of the thermal treatment to 6-7 $\mathrm{h}$ considerably decreases the subsequent setting and hardening time during the geopolymer preparation. This experiment has confirmed a well-organized clay lattice as the HI predicted.

The study of particle size distribution depicts the importance of small (under $4 \mu \mathrm{m}$ ) and very small (under $2 \mu \mathrm{m}$ ) particles. During the formation of the poly-condensed state, the solid particles dissolve in the alkali aqueous solution. This effect can be observed at the beginning of the mixing. The alkali aqueous solution slowly accepts the powdered solids (thermally treated clay) and after 5-10 min of mixing, the viscosity lowering is remarkable.

The HI $=1.043$ of the kaolin from the Sri Lanka deposit does not match the data of MAS-NMR. Nevertheless, the experimental preparation of the geopolymer has confirmed the MAS-NMR results because the setting and hardening time was short, as expected. Table 3 shows only kaolinite detected by XRD analyses. This tropical kaolin does not confirm the well-organized structure predicted by the HI value. 
Two by-products washed out from the sandstone (from distant places, namely Strelec and Provodin) are very similar in their HI values (1.19 and 1.22, respectively). In the case of Provodin, the exact data from MAS-NMR presented in Figure 2 show a higher content of four-coordinated aluminum ions because their amount is increased by the presence of feldspar (calculated and confirmed by XRD). This sample also has a significantly lower amount of $\mathrm{Al}^{3+}$ in the five-coordination (Line 2-the transformation in the metastable position). The second material, Strelec, has not been complemented by feldspar; its MAS-NMR result is similar to that of the Sedlec kaolin.

It should be mentioned that both types of kaolinitic clay of this origin (Strelec and Provodin) form a perfect geopolymer. Their high content of very fine inseparable particles of quartz sand (up to $45 \mathrm{wt} . \%$ and $58 \mathrm{wt}$. \% of the total weight in Strelec and Provodin, respectively) does not affect the geopolymer reaction because sand particles have the function of filler. Their results of HI calculation show a well-organized kaolinite lattice which explains their shorter setting but rather longer hardening. It is possible that the reading of the XRD patterns of some clay materials could be highly affected by an extremely high content of accompanying impurities, which would also negatively influence the subtraction of the value of At and the subsequent calculation of the HI. However, the HI calculation based on the measurement of peaks obtained by XRD analyses shows agreement in $63 \%$ of the kaolin samples studied. An exception is the sample from Sri Lanka. Moreover, the two types of kaolinitic clay from sandstone (Strelec and Provodin) are mixed with impurities, as a consequence of which the result of the HI calculation does not say anything about the degree of the orderliness of the clay lattices.

On the other hand, the exact data obtained by the MAS-NMR method are also affected by a specific error, namely the content of feldspar in the clay material shows an extremely high amount of four-coordinated aluminum ions. However, these ions are part of the crystal lattice of feldspar, as a result of which they do not participate in the geopolymer reaction.

For the evaluation of the ability of the local material to form a geopolymer when the MAS NMR is not available, it is optimal to use a combination of three methods, namely XRD, the measurement of particle size, and chemical analyses. Nevertheless, this proposed procedure does not replace ${ }^{27} \mathrm{Al}$ MAS NMR analysis, but it only offers a qualified estimate of whether the clay material is suitable for the preparation of geopolymers.

\section{Conclusions}

This work supports the studies on double-layer clay and confirms the importance of changes in the coordination of aluminum ion. The four-/five-coordinated aluminum ion in thermally treated clay can be attacked by alkalis and, together with connected silicon, transform the material into an amorphous geopolymer 3D net.

As the geopolymer technology is spread worldwide among the laboratories and scientific organizations working with very different types of kaolin and kaolinitic clay, the evaluation of a local material based on the recognition of the above-mentioned qualities would greatly facilitate their research. The XRD in the powdered state has confirmed the double-layer clay and chemical analyses have identified the quantities of accompanying minerals. Kaolin crystallinity degree, which has been determined by means of the $\mathrm{HI}$ or the other mentioned methods, is the main factor in the estimation of the dwell time at the maximum temperature of thermal activation. It has been shown that there are exceptions to the rules when the clay particles are bigger than $4 \mu \mathrm{m}$ or the HI calculation is affected by impurities, which changes one of the important data in the calculated formula.

This paper presents the results obtained using the commonly available methods and their combinations, which match in $63 \%$ with the most modern methods represented by ${ }^{27} \mathrm{Al}$ MAS-NMR in solid state. 
This work also identifies the imperfections of both. The data of the HI alone do not provide detailed information on kaolin ordering, but in combination with the results of XRD analyses, the HI is usable in the majority of cases for its simplicity. The decomposition of the MAS-NMR pattern (including possible statistical errors) does not indicate the necessity to prolong the dwell of activation. The possible content of feldspathoids in the clay material increases the total amount of four-coordinated $\mathrm{Al}^{3+}$ identified by MAS-NMR, but the feldspathoids are not involved in the formation of the geopolymer network.

It can be concluded that the kaolin or kaolinitical clay suitable for the "activation" or for the later formation of geopolymers can be identified through a combination of "classical" methods: XRD in the powdered state, calculation based on chemical analyses, and the measurement of particle size distribution. Most of the cases studied have confirmed the usefulness of defining the HI with special care given to the perfect reading of the XRD patterns.

Supplementary Materials: The following are available online at http://www.mdpi.com/2075-163X/10/10/852/s1, Figure S1: Geopolymer solid prepared from metakaolin Kadan, Figure S2: Geopolymer solid prepared from metakaolin Ledce, Figure S3: Geopolymer solid prepared from metakaolin Sedlec, Figure S4: Geopolymer solid prepared from metakaolin Strelec, Figure S5: Geopolymer solid prepared from metakaolin Vidnava, Figure S6: Geopolymer solid prepared from metakaolin Kaznejov, Figure S7: Geopolymer solid prepared from metakaolin Provodin, Figure S8: Geopolymer solid prepared from metakaolin Sri Lanka, Figure S9: Geopolymer solid prepared from metakaolin Ukraine, Figure S10: Geopolymer solid prepared from metakaolin Brazil "B", Figure S11: Geopolymer solid prepared from metakaolin Brazil "R", Figure S12: Comparison of infrared spectra of metakaolin Brazil "B" with corresponding geopolymer matrix, Figure S13: Comparison of infrared spectra of metakaolin Brazil " $R$ "with corresponding geopolymer matrix, Figure S14: Comparison of infrared spectra of metakaolin Kadan with corresponding geopolymer matrix, Figure S15: Comparison of infrared spectra of metakaolin Kaznejov with corresponding geopolymer matrix, Figure S16: Comparison of infrared spectra of metakaolin Ledce with corresponding geopolymer matrix, Figure S17: Comparison of infrared spectra of metakaolin Sedlec with corresponding geopolymer matrix, Figure S18: Comparison of infrared spectra of metakaolin Sri Lanka with corresponding geopolymer matrix, Figure S19: Comparison of infrared spectra of metakaolin Ukraine with corresponding geopolymer matrix, Figure S20: Comparison of infrared spectra of metakaolin Vidnava with corresponding geopolymer matrix, Figure S21: Comparison of infrared spectra of metakaolin Provodin with corresponding geopolymer matrix, Figure S22: Comparison of infrared spectra of metakaolin Strelec with corresponding geopolymer matrix, Figure S23: XRD pattern of kaolin Kadan, Figure S24: XRD pattern of kaolin Ledce, Figure S25:XRD pattern of kaolin Sedlec, Figure S26: XRD pattern of kaolin Strelec, Figure S27: XRD pattern of kaolin Vidnava, Figure S28: XRD pattern of kaolin Kaznejov, Figure S29: XRD pattern of kaolin Provodin, Figure S30: XRD pattern of kaolin Sri Lanka, Figure S31: XRD pattern of kaolin Ukraine, Figure S32: XRD pattern of kaolin Brazil "B", Figure S33: XRD pattern of kaolin Brazil "R".

Author Contributions: Conceptualization, T.H. and I.P.; methodology, I.P., K.U. and V.̌̌.; formal analysis, T.H.,

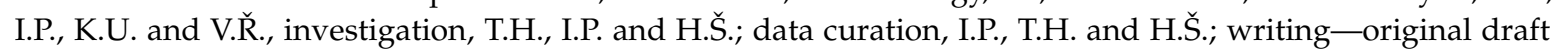
preparation, T.H. and I.P.; writing-review and editing I.P., T.H. and H.Š.; supervision, T.H. and I.P. All authors have read and agreed to the published version of the manuscript.

Funding: This work was carried out thanks to the support of the long-term project for the conceptual development of the research organization No. 67985891 and the Strategy AV21, activity of the Czech Academy of Sciences, the research program VP23-City as a Laboratory of Change: Historical Heritage and Place for Safe and Quality Life.

Acknowledgments: The authors would like to thank reviewers and editor for the manuscript revision.

Conflicts of Interest: The authors declare no conflict of interest.

\section{References}

1. Palomo, A.; Fernández-Jiménez, A. Nature of alkali aluminosilicate polymers; A ${ }^{29}$ Si MAS-NMR approach. In Proceedings of 3rd International Conference on Alkali Activated Materials-Research, Production and Utilization, Prague, Czech, 21-22 June 2007; Agency Action M: Prague, Czech, 2007; pp. 509-522.

2. Duxson, P.; Fernández-Jiménez, A.; Lukey, G.C.; Palomo, A.; van Deventer, J.S.J. Geopolymer technology: The current state of the art. J. Mater. Sci. 2007, 42, 2917-2933. [CrossRef]

3. Davidovits, J. Geopolymer: Chemistry\&Application, 4th ed.; Geopolymer Institute: Saint-Quentin, France, 2008.

4. Provis, J.L.; Bernal, S.A. Geopolymers and related alkali-activated materials. Annu. Rev. Mater. Res. 2014, 44, $299-327$. [CrossRef] 
5. Autef, A.; Joussein, E.; Gasgnier, G.; Pronier, S.; Sobrados, I.; Sanz, J.; Rossignol, S. Role of metakaolin dehydroxylation in geopolymer synthesis. Powder Technol. 2013, 250, 33-39. [CrossRef]

6. Langier-Kuzniarowa, A. Termogramy Mineralów Ilastych; Wydawnictwa Geologiczne: Warsawa, Poland, 1967.

7. Xu, H.; Van Deventer, J.S.J. The geopolymerisation of alumino-silicate minerals. Int. J. Miner. Process. 2000, 59, 247-266. [CrossRef]

8. Komnitsas, K.; Zaharaki, D. Geopolymerisation: A review and prospects for the minerals industry. Miner. Eng. 2007, 20, 1261-1277. [CrossRef]

9. Sanz, J.; Madani, A.; Serratosa, J.M.; Moya, J.S.; Aza, S. Aluminium-27 and Silicon-29 Magic-Angle Spinning Nuclear Magnetic Resonance Study of the Kaolinite-Mullite Transformation. J. Am. Ceram. Soc. 1988, 71, 418-421. [CrossRef]

10. Medri, V.; Fabbri, S.; Dedecek, J.; Sobalik, Z.; Tvaruzkova, Z.; Vaccari, A. Role of the morphology and the dehydroxylation of metakaolins on geopolymerization. Appl. Clay Sci. 2010, 50, 538-545. [CrossRef]

11. Singh, P.S.; Trigg, M.; Burgar, I.; Bastow, T. Geopolymer formation processes at room temperature studied by ${ }^{29} \mathrm{Si}$ and ${ }^{27} \mathrm{Al}$ MAS-NMR. Mater. Sci. Eng. A 2005, 396, 392-402. [CrossRef]

12. Amran, Y.M.; Alyousef, R.; Alabduljabbar, H.; El-Zeadani, M. Clean production and properties of geopolymer concrete: A review. J. Clean. Prod. 2020, 251, 119679. [CrossRef]

13. Liew, Y.M.; Heah, C.Y.; Kamarudin, H. Structure and properties of clay-based geopolymer cements: A review. Prog. Mater. Sci. 2016, 83, 595-629. [CrossRef]

14. Perná, I.; Hanzlíček, T.; Šupová, M. The identification of geopolymer affinity in specific cases of clay materials. Appl. Clay Sci. 2014, 102, 213-219. [CrossRef]

15. Rahier, H.; Wastiels, J.; Biesemans, M.; Willem, R.; Van Assche, G.; Van Mele, B. Reaction mechanism, kinetics and high temperature transformations of geopolymers. J. Mater. Sci. 2007, 42, 2982-2996. [CrossRef]

16. Hanzlíček, T.; Steinerová-Vondraková, M. Investigation of dissolution of alumina-silicates in aqueous alkaline solution under laboratory conditions. Ceramics 2002, 46, 97-103.

17. Hinckley, D.N. Variability in "crystallinity" values among the kaolin deposits of the coastal plain of Georgia and South Carolina. Clays Clay Miner. 1963, 11, 229-235. [CrossRef]

18. Plaçon, A.; Giese, R.F.; Snyder, R. The Hinckley Index for Kaolinites. Clay Miner. 1988, 23, 249-260. [CrossRef]

19. Dubois, J.; Murat, M.; Amroune, A.; Carbonneau, X.; Gardon, R. High-temperature transformation in kaolinite: The role of crystallinity and of the firing atmosphere. Appl. Clay Sci. 1995, 10, 187-198. [CrossRef]

20. Mitra, G.B. Structure defects in kaolinite. Z. Kristallogr. Z. Krist.-Cryst. Mater. 1963, 119, 161-175. [CrossRef]

21. Chmielová, M.; Weiss, Z. Determination of structural disorder degree using an XRD profile fitting procedure. Application to Czech kaolins. Appl. Clay Sci. 2002, 22, 65-74. [CrossRef]

22. Plançon, A.; Zacharie, C. An expert system for the structural characterization of kaolinites. Clay Miner. 1990, 25, 249-260. [CrossRef]

23. Aparicio, P.; Galán, E.; Ferrell, R.E. A new kaolinite order index based on XRD profile fitting. Clay Miner. 2006, 41, 811-817. [CrossRef]

24. Weiss, Z.; Kužvart, M. Jilové Minerály. Jejich Nanostruktura a Využití. (En: Clay Minerals. Their Nanostructure and Utilization). Karolinum Pres; Charles University: Prague, Republic, 2005. (In Czech)

25. Fitzgerald, J.J.; DePaul, S.M. Solid-State NMR Spectroscopy of Inorganic Materials: An Overview. In Solid-State NMR Spectroscopy of Inorganic Materials, ACS Symposium Series (Book 717); Fitzgerald, J.J., Ed.; American Chemical Society: Washington, DC, USA, 1999; pp. 2-133.

26. Kirkpatrics, R.J.; Cong, X.D. An introduction to 27Al and 29Si NMR spectroscopy of cements and concretes. In Applications of NMR Spectroscopy to Cement Science; Colombet, P., Grimmer, A.-R., Eds.; CRC Press: Amsterdam, The Netherlands, 1995; pp. 55-75.

27. Massiot, T.; Coté, B.; Taulelle, F.; Coutures, J.P. ${ }_{27} \mathrm{Al}$ MAS NMR of crystalline and amorphous materials. In Applications of NMR Spectroscopy to Cement Science; Colombet, P., Grimmer, A.-R., Eds.; CRC Press: Amsterdam, The Netherlands, 1995; pp. 153-169.

28. Stebbins, J.F. Quadrupolar NMR in the Earth Sciences. In NMR of Quadrupolar Nuclei in Solid Materials; Wasylishen, R.E., Ashbrook, S.E., Wimperis, S., Eds.; John Wiley \&Sons: Chichester, UK, 2012; pp. 387-415.

29. Ferone, C.; Liguori, B.; Capasso, I.; Colangelo, F.; Cioffi, R.; Cappelletto, E.; Di Maggio, R. Thermally treated clay sediments as geopolymer source material. Appl. Clay Sci. 2015, 107, 195-204. [CrossRef]

30. Xu, H.; Van Deventer, J.S.J. Geopolymerisation of multiple minerals. Miner. Eng. 2002, 15, 1131-1139. [CrossRef] 
31. Wang, M.R.; Jia, D.C.; He, P.G.; Zhou, Y. Influence of calcination temperature of kaolin on the structure and properties of final geopolymer. Mater. Lett. 2010, 64, 2551-2554. [CrossRef]

32. Hanzlicek, T.; Niznansky, D.; Dedecek, J.; Steinerova, M.; Straka, P.; Triskova, J. Discoloration of Fired Kaolinitic Clays (Study of $\mathrm{Fe}^{3+}$ Coordination by Mössbauer and UV-ViS-NIR Spectroscopy). J. Am. Ceram. Soc. 2007, 90, 2843-2848. [CrossRef] 